\title{
Significance of systemic endotoxaemia in inflammatory bowel disease
}

K R Gardiner, M I Halliday, G R Barclay, L Milne, D Brown, S Stephens, R J Maxwell, B J Rowlands

\begin{abstract}
Quantitative and qualitative disturbances in faecal flora suggest a role for enteric bacteria and their products in the pathogenesis of inflammatory bowel disease (IBD). This study investigated the hypothesis that systemically circulating endotoxins are of pathogenic significance in IBD by measuring antibody, cytokine, and acute phase protein responses. Systemic endotoxaemia was found in $\mathbf{8 8} \%$ patients with ulcerative colitis $(n=25)$ and 94\% with Crohn's disease $(n=31)$ during clinical relapse. Systemic endotoxaemia correlated positively with anatomic extent and clinical activity of ulcerative colitis. Circulating tumour necrosis factor (TNF) was detected in $40 \%$ of patients with ulcerative colitis and $45 \%$ with Crohn's disease. Plasma TNF concentrations correlated with clinical and laboratory measures of disease activity and were associated with a surgical outcome to the disease episode. Plasma soluble TNF receptor p55 concentration correlated positively with disease activity and endotoxin core antibody concentrations. Plasma IgG endotoxin core antibody concentrations were significantly increased in patients with Crohn's disease and correlated with systemic endotoxaemia. The presence of systemic endotoxaemia, its correlation with disease activity, disease extent, and endotoxin core antibody concentration and the detection of circulating TNF and soluble TNF receptors all support a pathogenic role for endotoxins in IBD.

(Gut 1995; 36: 897-901)
\end{abstract}

Department of Surgery, The Queen's University of Belfast K R Gardiner $M$ I HaHiday

R J Maxwell

B J Rowlands

The Blood Transfusion Service, Edinburgh G R Barclay L Milne

Celltech Research, Slough

D Brown

S Stephens

Correspondence to: Mr K Gardiner, Department of Surgery, The Queen's University of Belfast Institute of Clinical Science, Grosvenor Road, Belfast BT 12 6BJ, Northern Ireland.

Accepted for publication 24 October 1994
Keywords: inflammatory bowel disease, endotoxaemia.

Three findings have suggested that intestinal bacteria participate in the pathogenesis of inflammatory bowel disease (IBD): the histological resemblance of intestinal inflammation caused by infectious agents (Campylobacter jejuni, Yersinia enterocolitica, enteroinvasive Escherichia coli, and Mycobacterium paratuberculosis) to IBD, the presence of granulomas in Crohn's disease (CD) tissue, and the occurrence of the lesions of ulcerative colitis (UC) in a location that normally harbours a luxuriant bacterial population. ${ }^{1}$ However, studies attempting to isolate specific pathogens or using antimicrobial treatment in IBD have been inconclusive. ${ }^{23}$ Antibacterial antibody studies have shown that there is increased plasma cell exposure to bacterial antigens in
IBD patients, which implies that intraluminal bacteria or their products translocate across the intestinal wall. ${ }^{4}$ The occurrence of antibodies against multiple different species and different serotypes suggests that no single bacterial species or strain is implicated. It has been postulated that products of normal luminal bacteria such as endotoxins, peptidoglycans or formylated oligopeptides may underlie the initiation and perpetuation of intestinal inflammation. ${ }^{5-7}$ Indeed, experimental intestinal inflammation has been induced in the rabbit by intracolonic instillation of endotoxin and formalin, in the mouse, rat, and rabbit by intracolonic instillation of formylated oligopeptides, and in the rat by intramural injection of peptidoglycans. ${ }^{7-9}$

Circulating endotoxins have been repeatedly shown in patients with UC and in those with CD using a variety of techniques. ${ }^{51011}$ These studies have shown that systemic endotoxaemia is positively correlated with disease activity, radiological extent, the presence of intestinal ulceration, and plasma protein concentrations. It is not clear, however, whether systemic endotoxaemia in IBD is of pathogenic significance or an epiphenomenon reflecting a disrupted intestinal mucosal barrier. Administration of endotoxin to human volunteers and experimental animals induces many of the systemic findings in IBD: fever, tachycardia, chills, release of stress hormones, activation of complement, and release of vasoactive amines and platelet activating factor. ${ }^{12}$ Parenteral administration of endotoxin can also result in structural and functional abnormalities in the intestinal mucosa. ${ }^{13} 14$

The aim of this study was to investigate whether systemic endotoxins are of pathogenic significance in IBD by searching for evidence of a specific systemic immune response to endotoxin during active disease: production of endotoxin core antibody (EndoCAb) and of tumour necrosis factor (TNF). The glycolipid core of the endotoxin molecule is highly conserved between species and is associated with the endotoxic properties. ${ }^{15}$ TNF is a 157 amino acid protein secreted by activated macrophages in response to endotoxin and is believed to be responsible for many of the pathophysiological processes that follow endotoxaemia. ${ }^{16}$

\section{Methods}

PATIENTS

Patients admitted to hospital with suspected IBD or with a clinical relapse of previously 


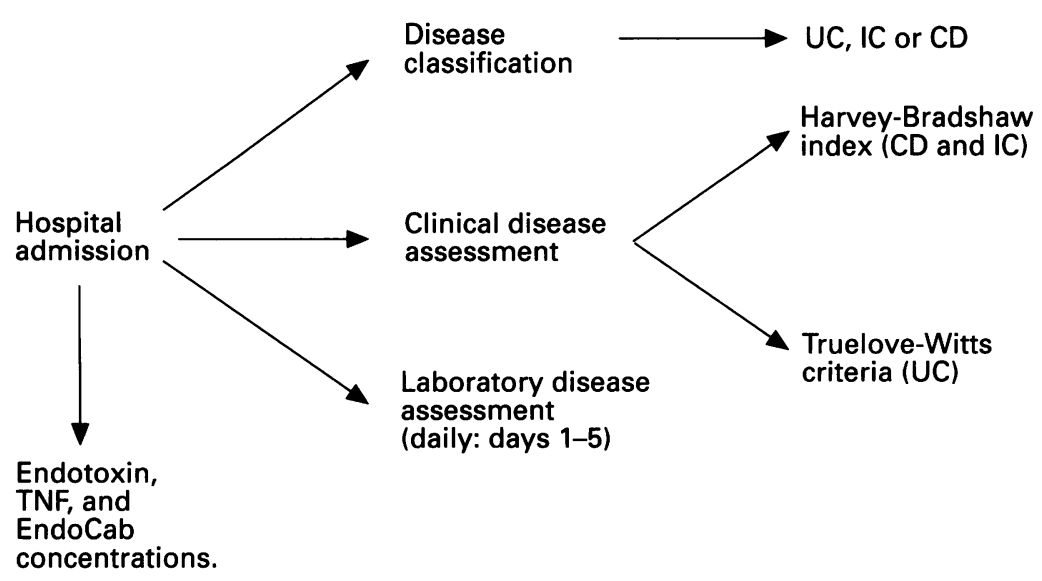

Outcome at 12 months.

Figure 1: Study experimental design.

diagnosed IBD were considered eligible for study (Fig 1). Patients discharged or undergoing surgery within five days of admission were removed from the study, as surgical trauma, in itself, induces an acute phase protein response. Patients were classified on the basis of standard clinical, radiological, and histological features as suffering from $U C, C D$, or indeterminate colitis (IC).

Control values for the EndoCAb assay (IgG and $\operatorname{IgM}$ ) were compiled from a study of 1024 blood donors. Control samples for the endotoxin and TNF assays were provided by over 100 healthy volunteers. This study was approved by the research ethical committee of the Faculty of Medicine, The Queen's University of Belfast.

\section{STUDY DESIGN}

Clinical indices of disease activity

Clinical assessment of disease activity was made on patients at admission, using the Truelove and Witts' categories ${ }^{17}$ for patients with UC and the Harvey-Bradshaw index ${ }^{18}$ for patients with $\mathrm{CD}$ or IC.

\section{Disease extent score}

The extent of disease in patients with UC and IC was arbitrarily quantified by awarding a score of one point (maximum five points) for involvement of each of the following in the disease process: rectum, sigmoid colon, descending colon, transverse colon, and ascending colon.

\section{Assays}

Plasma collected daily from patients (days 1 to 5 after admission) and healthy volunteers was assayed for endotoxin $(\mathrm{pg} / \mathrm{ml})$ using a quantitative chromogenic limulus amoebocyte lysate assay (Coatest Endotoxin, Quadratech, UK), for tumour necrosis factor (TNF) (pg/ml) using an enzyme linked immunosorbent assay (ELISA), ${ }^{19}$ and EndoCAb also using an ELISA. ${ }^{15}$ EndoCAb results are expressed as median units (MU) where $100 \mathrm{MU}$ is the median of each of the IgG and IgM EndoCAb ranges in 1024 blood donors. Positive endotoxaemia was defined as a plasma endotoxin concentration $>8.3 \mathrm{pg} / \mathrm{ml}(1 \mathrm{EU} / \mathrm{ml})$.

The p55 soluble TNF receptor was measured by ELISA. Briefly, microtitre plates were coated with SR13 monoclonal antibody to soluble p55 overnight at room temperature. Soluble receptors were detected using a second biotinylated monoclonal antibody $5 \mathrm{R} 5$ in combination with a streptavidin-peroxidase conjugate. The assay had a sensitivity of $0.5 \mathrm{ng} / \mathrm{ml}$ and a range of $0.5-100 \mathrm{ng} / \mathrm{ml}$.

Laboratory measures of disease activity Serum was assayed for $C$ reactive protein (CRP) (precipitin quantitation), $\alpha_{1}$ acid glycoprotein (rate nephelometry), albumin (bromocresol green), and alkaline phosphatase activity. Erythrocyte sedimentation rate (ESR), plasma viscosity (PV), and full haematological profile were also determined.

\section{Laboratory indices of disease activity}

Cooke and Prior $^{20}$ derived a simple laboratory index for IBD using only haemoglobin, albumin, and seromucoid ( $\alpha_{1}$ acid glycoprotein) concentrations. Positive values indicated health and negative values ill health. For this study, a modified Cooke-Prior score was calculated as only serum $\alpha_{1}$ acid glycoprotein concentration, rather than total seromucoids, was measured.

Modified Cooke-Prior score $=$

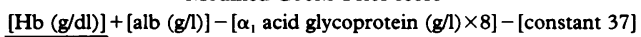
2

where $\mathrm{Hb}=$ haemoglobin concentration; $\mathrm{alb}=$ albumin concentration; and serum seromucoid concentration has been converted to serum $\alpha_{1}$ acid glycoprotein concentration.

\section{Outcome assessment}

Patients were classified into two groups according to outcome at six months after study: (a) those whose disease was in remission (asymptomatic) or under control (receiving acetylsalicylic acid or corticosteroids, or both); and (b) those having undergone surgical excision of diseased intestine.

\section{Calculations}

Results are expressed as mean (SEM). Data analysis was performed on a Macintosh LC personal computer using Kruskal-Wallis ANOVA, Spearman rank correlations, and Student's $t$ test (Statworks). Probabilities less than 0.05 were considered significant.

\section{Results}

\section{Patients details}

Sixty four patients with IBD were studied (UC: $n=25$, IC: $n=8, C D: n=31$ ) with a median age of 34.5 years (range 14-73); 34 male and 30 female. The study period 
TABLE I Laboratory disease activity assessment in IBD

\begin{tabular}{|c|c|c|c|}
\hline & $U C(n=25)$ & $I C(n=8)$ & $C D(n=31)$ \\
\hline Haemoglobin $(\mathrm{Hb})(\mathrm{g} / \mathrm{dl})$ & $12 \cdot 1(0 \cdot 6)$ & $11 \cdot 0(0 \cdot 8)$ & $11 \cdot 3(0 \cdot 3)$ \\
\hline White cell count $\left(\times 10^{6} / \mathrm{ml}\right)$ & $10 \cdot 6(0 \cdot 7)$ & $8.6(1.0)$ & $9.9(0.5)$ \\
\hline Platelet count $\left(\times 10^{6} / \mathrm{ml}\right)$ & $437.0(25 \cdot 9)$ & $462 \cdot 4(36 \cdot 6)$ & $511 \cdot 7(30 \cdot 0)$ \\
\hline $\operatorname{ESR}(\mathrm{mm} / \mathrm{h})$ & $49 \cdot 1(5 \cdot 4)$ & $59 \cdot 4(9 \cdot 0)$ & $73 \cdot 3(6 \cdot 5)$ \\
\hline Plasma viscosity (cp) & $1.69(0.03)$ & $1.69(0.05)$ & $1.79(0.03)$ \\
\hline $\mathrm{CRP}(\mathrm{mg} / \mathrm{l})$ & $35.8(10.0)$ & $51 \cdot 4(20 \cdot 3)$ & $68.9(11.7)$ \\
\hline$\alpha_{1}$ acid glycoprotein $(\mathrm{g} / \mathrm{l})$ & $1 \cdot 13(0.09)$ & $1.44(0 \cdot 21)$ & $1.53(0.08)$ \\
\hline Albumin $(g / 1)$ & $38.3(0.9)$ & $33 \cdot 4(2 \cdot 7)$ & $33 \cdot 7(1 \cdot 2)$ \\
\hline Alkaline phosphatase activity (U/l) & $98 \cdot 0(8 \cdot 0)$ & $101.9(11.5)$ & $157 \cdot 7(23 \cdot 9)$ \\
\hline
\end{tabular}

Data shown as mean (SEM)

represented the first presentation of IBD in eight patients. Patients with UC were classified using the Truelove-Witts criteria as mild $(n=5)$, moderate $(n=11)$, and severe $(n=9)$.

\section{Laboratory inflammatory assessment}

Table I summarises the laboratory data for the three diagnostic groups.

\section{Disease extent and disease activity}

There were significant correlations between the extent of UC and the serum concentrations of albumin $\left(r_{\mathrm{s}}=-0.48 ; \mathrm{p}=0.016\right)$, CRP $\left(r_{\mathrm{s}}=0.39 ; \mathrm{p}=0.05\right)$, and $\alpha 1$ acid glycoprotein $\left(r_{\mathrm{s}}=0.46 ; \mathrm{p}=0.019\right)$ as well as $\operatorname{ESR}\left(r_{\mathrm{s}}=0.42\right.$; $\mathrm{p}=0.035)$, platelet count $\left(r_{\mathrm{s}}=0.45 ; \mathrm{p}=0.024\right)$, and the Cooke - Prior score $\left(r_{\mathrm{s}}=-0.55\right.$; $p=0.004)$. For patients with IC, there were significant correlations of the extent of colitis with serum CRP concentration $\left(r_{\mathrm{s}}=0.73\right.$; $\mathrm{p}=0.041), \operatorname{ESR}\left(r_{\mathrm{s}}=0.73 ; \mathrm{p}=0.041\right)$, haemoglobin concentration $\left(r_{\mathrm{s}}=-0.73 ; \mathrm{p}=0.041\right)$, and the Truelove-Witts categories $\left(r_{\mathrm{s}}=0.80\right.$; $\mathrm{p}=0.016$ ).

\section{Systemic endotoxaemia (Table II)}

There was a significant positive correlation between the extent of IC and the peak systemic endotoxin concentration $\left(r_{\mathrm{s}}=0.75 ; \mathrm{p}=0.016\right)$. There was a weaker correlation between the number of endotoxaemic days and the Truelove-Witts classification of disease activity in patients with UC $\left(r_{\mathrm{s}}=0.41 ; \mathrm{p}=0.044\right)$. All controls had systemic endotoxin concentrations less than $10 \mathrm{pg} / \mathrm{ml}$.

TNF and TNF receptor concentrations (Table II) In the group with UC, peak TNF concentration was significantly correlated with Cooke-Prior score $\left(r_{\mathrm{s}}=-0.43 ; \mathrm{p}=0.033\right)$, Truelove-Witts categories $\left(r_{\mathrm{s}}=0.40 ; \mathrm{p}=0.046\right)$, and serum $\alpha_{1}$ acid glycoprotein concentration $\left(r_{\mathrm{s}}=0.41\right.$;

TABLE II Plasma endotoxin, TNF, TNF receptor, and EndoCAb concentrations in IBD

\begin{tabular}{lccr}
\hline & $U C(n=25)$ & $I C(n=8)$ & $C D(n=31)$ \\
\hline Peak plasma endotoxin (pg/ml) & $26 \cdot 1(4 \cdot 2)$ & $23 \cdot 6(6 \cdot 6)$ & $29 \cdot 1(5 \cdot 6)$ \\
Days endotoxaemic (max 5) & $2 \cdot 6(0 \cdot 4)$ & $1 \cdot 9(0 \cdot 6)$ & $2 \cdot 2(0 \cdot 2)$ \\
Peak plasma TNF (pg/ml) & $13 \cdot 9(5 \cdot 6)$ & $38 \cdot 8(19 \cdot 1)$ & $16 \cdot 6(5 \cdot 8)$ \\
Days positive for TNF (max 5) & $1 \cdot 0(0 \cdot 4)$ & $1 \cdot 4(0 \cdot 7)$ & $1 \cdot 1(0 \cdot 3)$ \\
Plasma p55 TNF receptor (ng/ml) & $8 \cdot 5(2 \cdot 4)$ & $12 \cdot 8(5 \cdot 2)$ & $12 \cdot 6(3 \cdot 1)$ \\
Mean plasma IgG EndoCAb (MU) & $123 \cdot 8(12 \cdot 6)$ & $215 \cdot 2(64 \cdot 5)$ & $638 \cdot 7(99 \cdot 3)$ \\
Mean plasma IgM EndoCAb (MU) & $74 \cdot 3(10 \cdot 3)$ & $77 \cdot 0(15 \cdot 7)$ & $97 \cdot 2(11 \cdot 5)$ \\
\hline
\end{tabular}

Significance: IgG EndoCAb: p<0.001 (Kruskal-Wallis). IgG EndoCAb: UC $v$ CD: $p<0.001$; UC $v$ IC: $\mathrm{p}=0.037$; IC $v$ CD: $\mathrm{p}=0.041$ (Student's $t$ test)

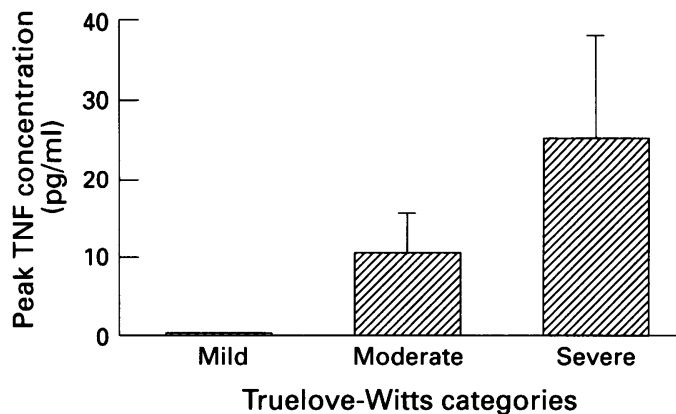

Figure 2: Peak TNF and disease activity in ulcerative colitis.

$\mathrm{p}=0 \cdot 04)$. The number of days positive for TNF was also significantly correlated with the CookePrior score $\left(r_{\mathrm{s}}=-0.44 ; \mathrm{p}=0.028\right)$ and the Truelove-Witts categories $\left(r_{\mathrm{s}}=0.44 ; \mathrm{p}=0.026\right)$. Figure 2 shows peak TNF concentration plotted against the Truelove-Witts categories. No detectable systemically circulating TNF was found in the control population.

The plasma concentration of the soluble TNF receptor p55 was significantly increased in all of the diagnostic groups when compared with controls $(2.3 \quad(0.2) \mathrm{ng} / \mathrm{ml}$; Student's $t$ test). Plasma p55 concentration correlated with serum concentrations of albumin $\left(r_{\mathrm{s}}=-0.31 ; \quad \mathrm{p}=0.018\right), \quad \mathrm{CRP} \quad\left(r_{\mathrm{s}}=0.31 ;\right.$ $\mathrm{p}=0.018)$, and $\alpha_{1}$ acid glycoprotein $\left(r_{\mathrm{s}}=0.34\right.$; $\mathrm{p}=0.009)$, with the Cooke-Prior score $\left(r_{\mathrm{s}}=-0.34 ; \mathrm{p}=0.009\right)$ and with plasma IgG $\left(r_{\mathrm{s}}=0.28 ; \mathrm{p}=0.035\right)$ and $\operatorname{IgM} \quad\left(r_{\mathrm{s}}=0.39\right.$; $\mathrm{p}=0.002)$ EndoCAb concentrations.

\section{Systemic EndoCAb response}

There was a significant increase in the plasma IgG EndoCAb concentration in the $\mathrm{CD}$ and IC groups when compared with healthy controls $(94 \cdot 3(3 \cdot 8))$ and with the UC group (Table II). There was a significant association between the distribution of $\mathrm{CD}$ and the mean plasma IgG EndoCAb concentration (Fig 3): plasma IgG EndoCAb concentration being significantly higher in patients with small bowel CD (929.6 (178.5)) when compared with patients with large bowel CD (340.5 (59.2); $p=0.006$, Student's $t$ test). In the CD group, there was also a positive correlation between the number of endotoxaemic days and the plasma concentrations of IgG $\left(r_{\mathrm{s}}=0.37 ; \mathrm{p}=0.038\right)$ and IgM $\left(r_{\mathrm{s}}=0.46 ; \mathrm{p}=0.009\right)$ EndoCAb.

\section{Treatment received}

In the group with UC, four patients were treated with aminosalicylic acid derivatives, six with systemic corticosteroids, and 14 with both aminosalicylic acid derivatives and systemic corticosteroids. In the group with IC, two patients were treated with systemic corticosteroids and four with both aminosalicylic acid derivatives and systemic corticosteroids. In the CD group, nine patients were treated with systemic corticosteroids, 11 with aminosalicylic acid derivatives and systemic corticosteroids, three with systemic corticosteroids and azathioprine, one with azathioprine and an elemental diet, and one with elemental diet 


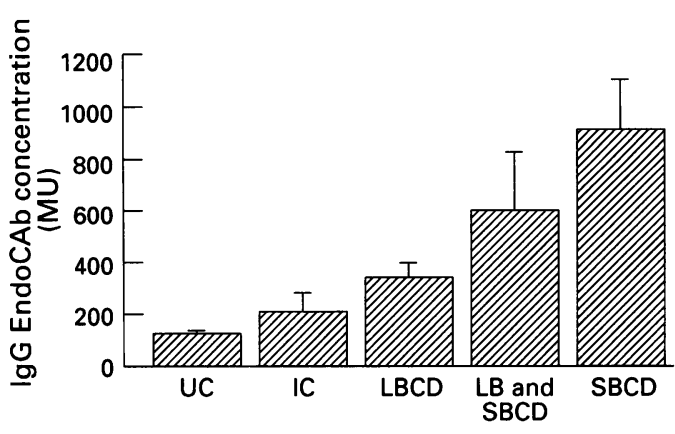

Figure 3: Relation of diagnosis and disease distribution to IgG EndoCAb concentration. $L B=$ large bowel; $S B=$ small bowel.

alone. There was no relation between treatment type or duration and results of systemic endotoxin or TNF measurements.

\section{Disease outcome}

For UC patients, outcome at six months after the study episode was classified as remission in 18 and surgical in seven (total abdominal colectomy). A surgical outcome was found to be significantly associated with a higher peak plasma TNF concentration $(p=0.04)$ (Kruskal-Wallis).

For patients with CD, outcome was classified as surgical in 10 and found to be significantly associated with higher serum $\alpha_{1}$ acid glycoprotein $(p=0.039)$ and CRP concentrations $(p=0.047)$, a higher platelet count $(p=0.043)$, increased ESR $(p=0.004)$, a lowered serum albumin concentration $(p=0.022)$, and a lower Cooke-Prior score $(p=0.043)$ (Kruskal-Wallis).

\section{Discussion}

Systemic endotoxaemia is often such a transient feature of septic illness that an inflammatory cascade can be activated and clinical disturbances occur without simultaneously detectable endotoxin. ${ }^{21}$ It was therefore felt necessary in this study, not only to measure plasma endotoxin concentration and to investigate for a correlation between systemic endotoxaemia and disease activity, but also to search for evidence of a specific immune response to endotoxin as evidence of endotoxicosis. Disease activity was assessed using both clinical and laboratory measures of activity. ${ }^{171820}$ Extent of colonic disease was measured using a simple scoring system and was found to correlate well with laboratory measures of inflammation in both UC and IC.

The desire to detect endotoxins at low concentrations in human blood has led to development of a range of tests from the epinephrine skin reaction, to the limulus gelation test, which was at least 10 times more sensitive to the limulus amoebocyte lysate assay. ${ }^{22}$ The limulus amoebocyte lysate bioassay is highly sensitive being capable of detecting femtogram quantities of standard endotoxin. ${ }^{22}$ Systemic endotoxaemia has been shown to occur where the intestinal mucosal barrier is damaged by trauma, infection (typhoid fever, $E$ coli enteritis, helminthiais), ischaemia or neoplasia. ${ }^{2324}$ Patients with other intestinal diseases were therefore thought to be unsuitable controls. None of the 100 healthy volunteers was positive for endotoxaemia, which is in agreement with other studies. ${ }^{22}$

Systemic endotoxaemia was found in each of the diagnostic groups: at least one endotoxaemic episode was identified in $88 \%$ patients with UC ( $52 \%$ samples positive), $75 \%$ patients with IC (38\% samples positive), and $94 \%$ patients with CD (45\% samples positive). Systemic endotoxaemia was found to correlate positively with the extent (IC) and activity (UC) of the disease. These results are in close agreement with those of existing reports of systemic endotoxaemia in IBD. ${ }^{5} 1011$

Circulating TNF was detected in $40 \%$ patients with UC (22\% samples positive), $63 \%$ patients with IC ( $25 \%$ samples positive), $45 \%$ patients with CD (19\% samples positive), and none of 100 controls. In the UC group, peak TNF concentration (and the number of TNF positive days) was significantly correlated with clinical (Truelove-Witts) and laboratory measures of disease activity (Cooke-Prior score and $\alpha_{1}$ acid glycoprotein concentration). Also in the UC group a surgical outcome was found to be significantly associated with peak plasma TNF concentrations. MacDonald et al ${ }^{25}$ detected TNF in the plasma of two of five children with active CD and two of four with active UC. In addition, Murch et $a l,{ }^{26}$ have reported an appreciable rise in circulating TNF in children with a relapse of UC and colonic CD but not small bowel CD.

Two soluble TNF receptors (p55 and p75) are released by cells during inflammation and are thought to modulate the effects of TNF. ${ }^{27}$ High concentrations of these TNF receptors have been described in the serum samples of patients with rheumatoid arthritis and osteomyelitis. ${ }^{27}$ In this study, the soluble TNF receptor p55 was found to be significantly increased in each of the diagnostic groups and to correlate with laboratory measures of disease activity and plasma EndoCAb' concentrations. An inhibitor of TNF toxicity has previously been described in the serum of patients with CD but not in healthy controls. ${ }^{28}$ More recently, van Deventer et $a l^{29}$ have reported significant increases in both p 55 and p75 TNF receptors in patients with active $C D$.

There are two main possible sources of this circulating TNF: overspill from macrophages within inflamed intestine or secretion by activated circulating monocytes. ${ }^{26}$ Significantly increased concentrations of TNF have been detected in the stools of children with active UC or CD and faecal TNF concentration has therefore been suggested as a marker of disease activity. ${ }^{30}$ Mahida et al, ${ }^{31}$ however, found no significant difference in the production of TNF by mucosal cells from colon with IBD compared with normal colon. Regarding peripheral blood monocytes, Mazlam and Hodgson $^{32}$ found that in vitro release of TNF by these cells correlated positively with the serum concentrations of CRP and $\alpha_{1}$ acid glycoprotein in patients with $C D$. The 
supernatant from these cultured monocytes stimulated the release of $\alpha_{1}$ acid glycoprotein from a liver cell line, the amount of which correlated with the TNF concentration within the supernatant. ${ }^{32}$ The increases in the plasma concentrations of TNF and soluble TNF receptors and the positive correlation between measures of TNF activity (plasma TNF concentration, plasma TNF receptor concentration, and in vitro monocyte TNF production) and serum $\alpha_{1}$ acid glycoprotein concentration all suggest that TNF is of pathogenic significance in patients with IBD.

Plasma IgG EndoCAb concentrations were significantly increased in CD patients compared with the UC and IC groups. Analysis of these results according to the distribution of the disease showed the highest IgG EndoCAb concentrations in patients with small bowel CD. Intermediate concentrations were found in patients with $\mathrm{CD}$ of both large and small intestines and lowest concentrations in those with colonic inflammation only. As might have been predicted, patients with IC had intermediate plasma IgG anti-CGL antibody concentrations as this group probably contains patients with UC and patients with $C D$. A positive correlation was found between systemic endotoxaemia and the plasma concentrations of IgG and IgM EndoCAb (CD). The finding that the plasma IgG EndoCAb concentration was highest in patients with small intestinal CD may be explained by the much greater permeability of the mucosal barrier of the small intestine (130-fold) to macromolecules compared with that of the colon. ${ }^{33}$ A greater absorption of endotoxins may therefore result from the increases in both intestinal permeability and intraluminal bacterial counts in active small bowel CD compared with those patients with Crohn's colitis. ${ }^{34} 35$

The high incidence of systemic endotoxaemia in this group of patients with active IBD, the significant correlations of systemic endotoxaemia with both disease activity and extent, the presence of circulating TNF (and soluble TNF receptors), and the specific antibody response to endotoxin (IgG EndoCAb) all support a pathogenically significant role for endotoxaemia in these diseases. The difference in EndoCAb concentrations between patients with UC and CD (despite the lack of difference in systemic endotoxin concentrations) is unexplained but may prove of value in discriminating between these two diseases.

This study has been presented in part at the 74 th meeting of the Surgical Research Society and has appeared in abstract form (Br F Surg 1991; 78: 1488A).

We wish to acknowledge support from the Eastern Health and Social Services Board, Northern Ireland and to thank Mervyn McCaigue PhD and Pauline Erwin BSc for their help with the endotoxin assay and Fiona Galloway for optimising and validating the soluble TNF receptor assay.

1 Tytgat GNJ, Mulder CJJ. The aetiology of Crohn's disease. Int 7 Colorectal Dis 1986; 1: 188-92.

2 Parent K, Mitchell P. Cell wall-defective variants of pseudomonas-like (Group Va) bacteria in Crohn's disease. Gastroenterology 1978; 75: 368-72.

3 Kobayashi K, Blaser MJ, Brown WR. Immunohistochemical examination for mycobacteria in intestinal tissues from patients with Crohn's disease. Gastroenterology 1987; 92: 436-42.

4 Matthews N, Mayberry JF, Rhodes J, Neale L, Munro J, Wensinck F. Agglutinins to bacteria in Crohn's disease. Gut 1980; 21: 376-80.
5 Aoki K. A study of endotoxaemia in ulcerative colitis and Crohn's disease. I. Clinical study. Acta Med Okayama 1978; 32: 147-58.

6 Sartor RB, Bond TM, Schwab JH. Systemic uptake and intestinal effects of luminal bacterial cell wall polymers in rats with acute colonic injury. Infect Immun 1988; 56: 2101-8.

7 LeDuc LE, Nast CC. Chemotactic peptide-induced acute colitis in rabbits. Gastroenterology 1990; 98: 929-35.

8 Hotta $T$, Yoshida N, Yoshikawa T, Sugino S, Kondo $M$. Lipopolysaccharide-induced colitis in rabbits. Res Exp Med 1986; 186: 61-9.

9 Sartor RB, Cromartie WJ, Powell DW, Schwab JH. Granulomatous enterocolitis induced in rats by purified bacterial cell wall fragments. Gastroenterology 1985; 89: 587-95.

10 Colin R, Grancher T, Lemeland J-F, Hecketsweiler P, Galmiche JP, Le Grix A. Recherche d'une endotoxinemie dans les entero-colites inflammatoires cryptogenetiques. Gastroenterol Clin Biol 1979; 3: 15-9.

11 Wellmann W, Fink PC, Benner F, Schmidt FW. Endotoxaemia in active Crohn's disease. Treatment with whole gut irrigation and 5-aminosalicylic acid. Gut 1986; 27: 814-20.

12 Sturk A, van Deventer SJH, Wortel $\mathrm{CH}$, Levels JH, ten Cate JW, Büller HR. Detection and clinical relevance of human endotoxaemia. Z Med Lab Diagn 1990; 31: human

13 Walker RI, Porvaznik MJ. Disruption of the permeability barrier (Zonula Occludens) between intestinal epithelial cells by lethal doses of endotoxin. Infect Immun 1978; 21: 655-8.

14 O'Dwyer ST, Michie HR, Ziegler TR, Revhaug A, Smith RJ, Wilmore DW. A single dose of endotoxin increases intestinal permeability in healthy humans. Arch Surg 1988; 123: 1459-64.

15 Barclay GR, Scott BB. Serological relationships between Escherichia coli and Salmonella smooth- and roughmutant lipopolysaccharides as revealed by enzyme-linked immunosorbent assay for human immunoglobulin G antiendotoxin antibodies. Infect Immun 1987; 55: 2706-14.

16 Beutler B, Cerami A. Cachectin: more than a tumor necrosis factor. $N$ Engl $\mathcal{Y}$ Med 1987; 316: 379-85.

17 Truelove SC, Witts LJ. Cortisone in ulcerative colitis. Final report on a therapeutic trial. $B M \mathcal{F} 1955 ; 2$ : $1041-8$.

18 Harvey RF, Bradshaw JM. A simple index of Crohn's disease activity. Lancet 1980; i: 514

19 Engelberts J, Moller A, Schoen GJM, van der Linden CJ. Evaluation of the measurement of human TNF in plasm by ELISA. Lymphokine Cytokine Res 1991; 10: 69-74.

20 Cooke WT, Prior P. Determining disease activity in inflam matory bowel disease. 7 Clin Gastroenterol 1984; 6: 17-25.

21 van Deventer SJH, Buller HR, ten Cate JW, Sturk A, Pauw W. Endotoxaemia: an early predictor of septicaemia in febrile patients. Lancet 1988; i: $605-9$.

22 Fink PC, Lehr I, Urbaschek RM, Zozak J Limulus amoebocyte lysate test for endotoxemia: investigations with a femtogram sensitive spectrophotometric assay. Klin Wochenschr 1981; 59: 213-8.

23 Magliulo E, Scevola D, Fumarola D. Limulus test in Escherichia coli enteritis. Lancet 1975; i: 407.

24 Fossard DP, Kakkar VV. The limulus test in experimenta and clinical endotoxaemia. Br F Surg 1974; 61: 798-804

25 MacDonald TT, Hutchings P, Choy M-Y, Murch S, Cooke A. Tumour necrosis factor-alpha and interferon-gamma production measured at the single cell level in normal and inflamed human intestine. Clin Exp Immunol 1990; 81: 301-5.

26 Murch $S H$, Lamkin VA, Savage MO, Walker-Smith JA MacDonald TT. Serum concentrations of tumour necrosis factor $\alpha$ in childhood chronic inflammatory bowel disease. Gut 1991; 32: 913-7.

27 Chikanza IC, Roux-Lombard P, Dayer J-M, Panayi GS Tumour necrosis factor soluble receptors behave as acute phase reactants following surgery in patients with rheumatoid arthritis, chronic osteomyelitis and osteoarthritis. Clin Exp Immunol 1993; 92: 19-22.

28 Foley N, Lambert C, McNicol M, Johnson N, Rook GAW. An inhibitor of the toxicity of tumour necrosis factor in the serum of patients with sarcoidosis, tuberculosis and Crohn's disease. Clin Exp Immunol 1990; 80: 395-9.

29 van Deventer SJH, Jansen J, van der Poll T, Godfried M, ten Cate JW. Soluble TNF receptors as a disease severity marker in inflammatory and infectious diseases. marker in inflammatory and infectious diseases. [Abstract]. In: Proceedings of the International

30 Braegger CP, Nicholls S, Murch SH, Stephens S, MacDonald TT. Tumour necrosis factor alpha as a marker of intestinal inflammation. Lancet 1992; 339: 89-91.

31 Mahida YR, Wu K, Lamming CED, Jewell DP, Hawkey CJ. Human colonic tumour necrosis factor-a (TNFa) production. Gastroenterology 1989; 96: A313.

32 Mazlam MZ, Hodgson HJF. Peripheral blood monocyte cytokine production and acute phase response in inflammatory bowel disease. Gut 1992; 33: 773-8.

33 Warshaw AL, Bellini CA, Walker WA. The intestinal mucosal barrier to intact antigenic protein. Difference between colon and small intestine. Am f Surg 1977; 13: $55-8$.

34 Jenkins RT, Jones DB, Goodacre RL, Collins SM, Coates G, Hunt RH, et al. Reversibility of increased intestinal permeability to ${ }^{51} \mathrm{Cr}$-EDTA in patients with gastrointestinal inflammatory disease. $A m$ f Gastroenterol 1987; 82. 1159-64.

35 Wensinck F, Custers-van Lieshout LMC, PoppelaarsKustermans PAJ, Schröder AM. The faecal flora of patients with Crohn's disease. $\mathcal{f}$ Hyg 1981; 87: 1-12. 